\title{
İnsansız Hava Araçlarının Kıyı Çizgisinin Belirlenmesinde Kullanılabilirliğinin Araştırılması
}

\author{
Nedim Onur AYKUT ${ }^{1}$ \\ ${ }^{1}$ Yıldız Teknik Üniversitesi, İnşaat Fakültesi, Harita Mühendisliği Bölümü, İstanbul. \\ (oaykut@yildiz.edu.tr) ORCID ID 0000-0002-5052-6217
}

\begin{abstract}
$\ddot{\mathbf{O z}}$
Kıyı izleme, doğal kaynakların yönetimi, çevresel planlama ile ilgili konularda hayati bir rol oynamaktadır. Kıyı alanlarında kıyı erozyonu, sediman taşınımı ve kıyı morfodinamiğinin değişimi sadece doğal etkenlerden değil aynı zamanda insan kaynaklı da olabilmektedir. Gelişen teknoloji ile insansız hava araçları lokal alanlarda hızlı, güvenilir veri toplama araçları olarak kullanılmaya başlanmıştır. Sunulan çalışmada Terkos bölgesi "Sürdürülebilir Kıyı Bölgesi İzleme Modeli İçin İnsansız Hava Araçları Entegrasyonu-Üç Boyutlu Otomatik Kıyı Ekstraksiyonu ve Analizi" başlıklı "TÜBİTAK Projesi (Proje No: 115Y718)" kapsamında üretilen ortofoto görüntü kullanılmıştır. GNSS ölçüleri ve elle sayısallaştırma sonuçları karşılaştırılarak insansız hava araçlarının, uluslararası standartlar çerçevesinde kıyı çizgilerinin belirlenmesindeki kullanım olanakları araştırılmıştır.
\end{abstract}

Anahtar Kelimeler: Insansız hava aracı, kıyı çizgisi, fotogrametri, ortofoto, GNSS

\section{The Research for Usability of Unmanned Aerial Vehicles in Coastal Line Determination}

Monitoring the coastal line is playing a vital role for management of natural resources and environmental planning. Coastal erosion, sediment transport and coastal morpho dynamics changes can be occurred in coastal areas because of not only natural factors but also human-induced effects. Unmanned aerial vehicles have been used as fast, reliable data collection vehicles in local areas by developing technology. The orthophotos, which were produced in the scope of a TUBITAK Project (Project No: 115Y718) titled "Integration of Unmanned Aerial Vehicles for Sustainable Coastal Zone Monitoring Model - Three-Dimensional Automatic Coastline Extraction and Analysis: Istanbul-Terkos Example", have been used in this study. It has been investigated the usage possibilities of unmanned aerial vehicles in the determination of coastal lines within the framework of international standards by comparing the results of real-time kinematic GNSS measurements and manual digitization.

Keywords: Unmanned aerial vehicles, coastal line, photogrammetry, orthophotos, GNSS

\section{GíRiş}

Üç tarafı denizlerle çevrili ülkemizde yaklaşık 8300 kilometre uzunluğunda kıyı şeridi yer almaktadır. Kıyı alanları hem turistik hem de yerleşim alanı olarak önemli bir yere sahiptir.
Kıyı alanlarının yoğun bir gelişme içinde olması, turistik tesisler ve bazı eğlence anlayışları bu alanların bozulmasına yol açabilmektedir (Yüksel, 2005). Kıyı alanları hassas nitelikleri ile erozyona eğilimli alanlar olup, bu alanların sürekli izlenmesi ve korunması gerekmektedir.

\footnotetext{
* Sorumlu Yazar
} 
Kıyı erozyonunun önlenmesi, kıyıların su baskınlarından korunması, kıyı alanlarına limanların planlanması, tasarımı ve yapımı, limanların kumlanma etkisine karşı korunmaları, vb. kı1 mühendisliği uygulamalarında (Yüksel, 1998) hidrodinamik yapının belirlenmesi ve modellenmesi gerekmektedir.

Kıyı çizgisinin ölçülmesi önceleri yersel yöntemler ile yapılmakta olup, uydu teknolojilerinin gelişmesiyle gerçek zamanlı kinematik ölçümler ile yapılır hale gelmiştir (Aydın, 2005). Kıyı değişimlerinin izlenmesi uzun yıllar boyu araştırmaların konusu olmuştur (Dornbusch vd., 2006). Uzaktan algilama teknikleri geleneksel yöntemlere oranla daha hızlı ve güvenilir bir şekilde kıyı çizgilerinin belirlenmesinde kullanılabilmektedir (Bayram vd., 2017). İnsansız hava araçlarının (İHA) sivil amaçlı kullanımı son yıllarda önemli ölçüde artmıştır. Ekonomik ve fonksiyonel faydalar göz önünde bulundurulduğunda hem ticari üreticiler hem de sivil kullanıcılar için İHA' lar önemli bir pazar kapasitesine ulaşmıştır (Stöcker, vd., 2017). İHA teknolojisinin uzaktan algilama ile entegrasyonu, çevre ile ilgili araştırmalar için veri analizi ve modellemeyi mümkün kılmıştır (Cheng, vd. 2014). Günümüzde, İHA sistemleri yoğunlukla yüzey analizi ile ilgili çalışmalarda kullanılmaktadır. Örneğin Peter, vd. (2014) İHA-kamera verilerini kullanarak toprak erozyonunu izlemişlerdir. Bunun yanında, özellikle kıyı alanlarında da artan bir kullanıma sahiptir (Gonçalves, vd. 2015; Barazzetti, vd. 2010). Bayram, vd. (2016) IHA-LIDAR ve IHA-Kamera verileri kullanarak otomatik kıyı çizgisi çıkartılmasına yönelik bir yöntem önermişlerdir. Yoo ve Oh, (2016) İHA-Kamera sistemini kullanarak kıy1 erozyonunun üç boyutlu (3B) belirlenmesi üzerinde çalışmışlardır. Nikolakopoulos, vd. (2017) Yunanistan'daki kıyı alanlarının SfM yöntemi ile izlenmesi için İHA-Kameray1 kullanmışlardır. Esposito, vd. (2017) kıyı bölgelerinde İHA-Kamera sistemi ile kı1 erozyonunu belirlemek için çalışmış ve SfM yöntemiyle elde edilen nokta bulutlarını karşılaştırmıştır.

Sunulan çalışmada, Karadeniz'in batısında, İstanbul/Terkos bölgesinde, yaklaş1k $1 \mathrm{~km}$ uzunluğundaki kıyı çizgisi hem gerçek zamanlı kinematik yöntem ile hem de İHA ile çekilen görüntülerden elde edilen ortofotoların elle sayısallaştırılmasıyla belirlenmiştir. Yapılan karşılaştırmalardan hesaplanan konum doğruluğunun Uluslararası Hidrografi Örgütünün öngördügü kıyı çizgisi belirleme standartlarına uygun olup olmadığ incelenmiştir.

\section{MATERYAL VE YÖNTEM}

Kıyı çizgisinin belirlenmesinde kullanılan yöntemlere değinmeden önce kıyı ile ilgili bazı kavramların açıklanmasında yarar bulunmaktadir.

\subsection{Kıyı ile ilgili Tanımlamalar}

17.04.1990 tarih ve 20495 say1lı Resmî Gazetede yayınlanan 3621 say1lı Kıy1 Kanununa göre;

Kıyı, kıyı çizgisi ile kıyı kenar çizgisi arasındaki alanı;

Kıyı Çizgisi, deniz, tabii ve suni göl ve akarsularda, taşkın durumları dişında, suyun karaya değdiği noktaların birleşmesinden oluşan çizgiyi;

Dar Kıyı ise kıyı kenar çizgisinin, kıyı çizgisi ile çakışmasını ifade etmektedir.

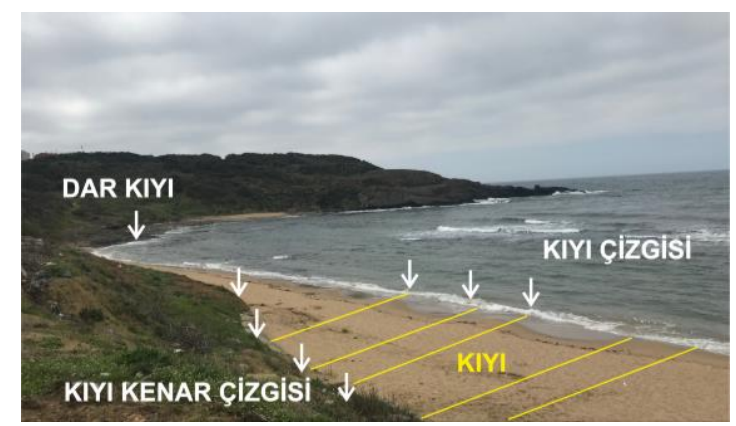

Şekil 1. Kıyı ile ilgili gösterimler

\subsection{Kıyı Çizgisinin Uluslararası Standartlara göre Belirlenme Doğruluğu}

Uluslararas1 Hidrografi Örgütü (IHO) Hidrografik Ölçme Standartları Özel Yayın No: 44/5 (2008)' e göre, ölçme alanları özel derece, 1.derece a ve b ile 2.derece olmak üzere 4 kısımda tanımlanmıştır. Özel derece alanlar derinliği 40 metreden sı $\breve{g}$, limanlar, yanaşma ve demirleme yerleri ve gemilerin omurga-altı geçiş derinliğinin kritik olduğu kanallardır. 1a derece alanlar ise 100 metreden sığ derinliğe sahip alanlardır. Bu alanlarda 
omurga-altı geçiş derinliği özel derece alanlara göre daha az kritik olup, yaklaşma suları ve gemilerin geçiş yolları bu alanlara örnek olarak verilebilir.1b derece alanlar omurga-altı geçiş derinliğinin kritik olmadığ 100 metreden sığ alanlar, 2.derece alanlar ise 100 metreden derin alanlardır.

Uluslararası Hidrografik Ölçme Standartlarına göre, kıyı çizgisi ölçümündeki konumlandırma doğruluğu Tablo1' de görülmektedir.

Tablo 1. Kıyı Çizgisi Belirlemede Asgari Standartlar (IHO, 2008)

\begin{tabular}{lcccc}
\hline Alan Tanımları & Özel & $\mathbf{1 a}$ & $\mathbf{1 b}$ & $\mathbf{2}$ \\
\hline $\begin{array}{l}\text { Kıyı çizgisi ve seyir } \\
\text { için daha az önemli } \\
\text { topografik } \\
\text { cisimlerin konumu } \\
(\mathrm{p}=0.05)\end{array}$ & $10 \mathrm{~m}$ & $20 \mathrm{~m}$ & $20 \mathrm{~m}$ & $20 \mathrm{~m}$ \\
& & & & \\
\hline
\end{tabular}

\subsection{Araştırma Alanı}

Araştırma alanı, Marmara Bölgesinde Batı Karadeniz kıyıları olarak seçilmiştir (Şekil 2). 20 Eylül 2017 tarihinde 115 Y718 no.lu TÜBİTAK projesi kapsamında insansiz hava aracı kullanılarak kıyı alanının görüntüleri çekilmiştir (Şekil 3).

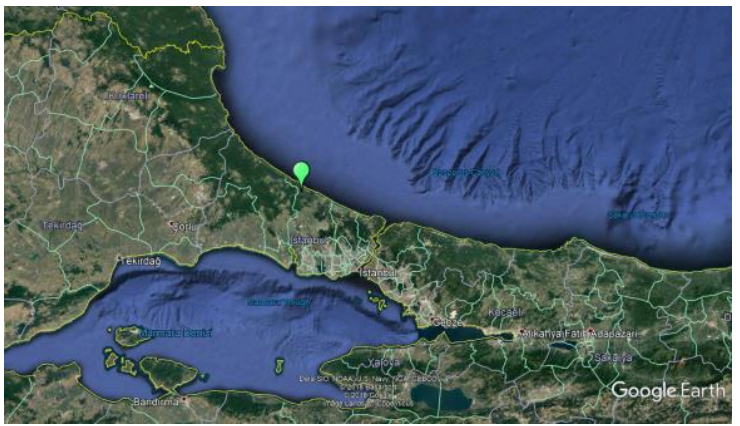

Şekil 2. Batı Karadeniz' de Yer alan Araştırma Alanı (GoogleEarth)

Çekilen görüntülerin, 41'22'27.52'K Enlemi ve $28^{\circ} 34^{\prime} 38.35 \mathrm{D}$ Boylamından başlayarak Doğuya doğru yaklaşı 1 kilometrelik kısmından yararlanılmıştır.

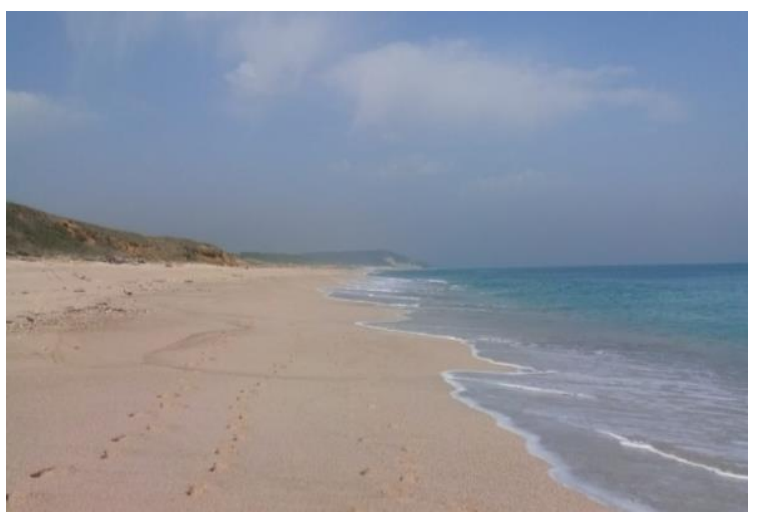

Şekil 3. Ölçümlerin Yapıldığı Karadeniz Kıyısı

\subsection{Veri Toplama Yöntemleri}

Kıyı alanlarının belirlenmesinde DJI Phantom 4 Pro İHA'sından yararlanılmıştır. Bu araçta, 1" CMOS sensör ile 20 MP özelliklerinde bir kamera bulunmaktadır (Dji, 2018).

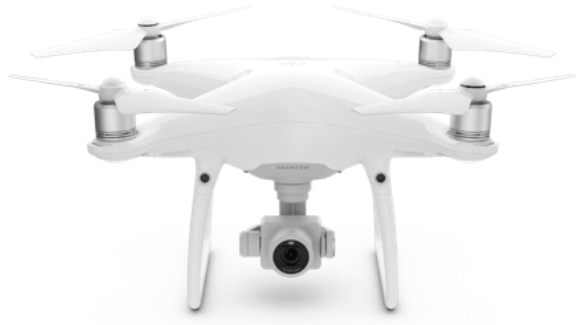

Şekil 4. Phantom 4 Pro İHA

Kıyı çizgileri gerçek zamanlı kinematik (RTK) GNSS yöntemi ile ölçülmüştür. Topcon Hyper Pro çift frekanslı GNSS alıcıları ile kıyı çizgisi boyunca yürüyerek yaklaşık 20-30 metrede bir ölçümler gerçekleştirilmiştir. RTK GNSS ölçümlerinde CORS-TR ağından yararlanılarak sanal referans yöntemi kullanılmış ve kıyı çizgisinin koordinat değerleri belirlenmiştir.

Ortofoto üretimi için İHA-Kamera uçuşları 70 m yükseklikten, \%80, \%70 bindirme oranları ile gerçekleştirilmiştir. Uçuştan önce test alanında 25 adet yer kontrol noktasi tesis edilmiștir. Kontrol noktalarının ve referans kıyı çizgisinin koordinatları RTK GNSS yöntemi ile belirlenmiştir. Ortofoto üretimi aşamasında SfM yöntemi ile nokta bulutu verisi elde edilmiş ve ardından kıyı alanının $1.96 \mathrm{~cm}$ yer örnek aralığında ortofotosu üretilmiştir. 


\subsection{Verilerin Analizi}

Kıyı çizgileri CAD ortamında elle 3 farklı kişi tarafından sayısallaştırılmıştır. Çalışmada GNSS ölçümleri ile toplanan koordinat değerleri referans veri olarak kabul edilmiştir. Kıyı çizgilerinin birbirleriyle karşılaştırılması için, 1080 metre uzunluğundaki kıyı boyunca 10 metre ara ile enine kesitler çizilmiştir (Şekil $5)$.

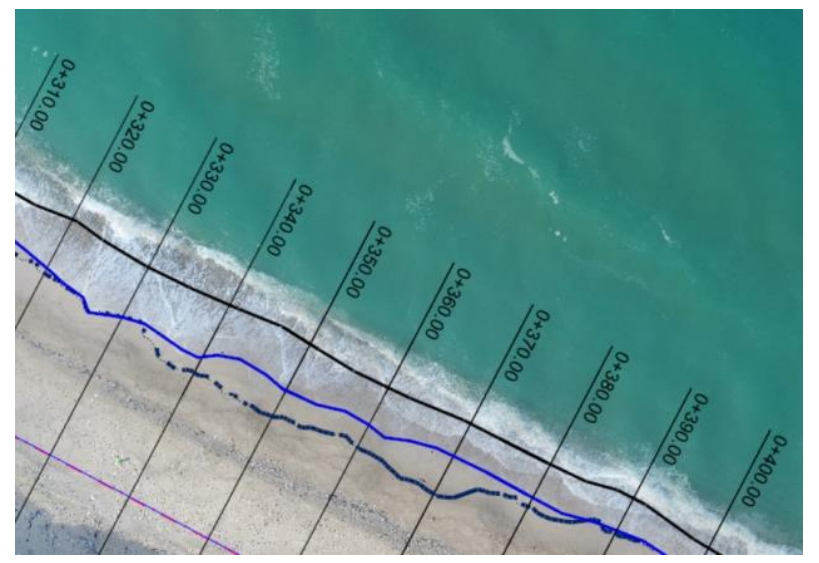

Şekil 5. Ortofoto harita ve enine kesitler

Üç farklı kişi tarafından yapılan sayısallaştırma sonucu elde edilen kıyı çizgilerinin kesitleri kestiği noktaların koordinatlarının belirlenmesinin ardından bu değerlerin ortalamaları alınarak kıyı boyunca ortalama bir kıy1 çizgisi elde edilmiştir. GNSS ölçümlerinden elde edilen kıyı çizgisi referans (bilinen) olarak kabul edilmiş ve $\varepsilon_{X}$ ve $\varepsilon_{Y}$ hataları (Şekil 6) koordinat farklarından Eşitlik 1 ve 2'e göre hesaplanmıştır.

$$
\begin{aligned}
& \varepsilon_{X(i)}=X_{\text {Say }(i)}-X_{R T K(i)} \\
& \varepsilon_{Y(i)}=Y_{\text {Say }(i)}-Y_{R T K(i)}
\end{aligned}
$$

$R M S_{\text {konum }}=\sqrt{\frac{[\varepsilon \varepsilon]_{X}+[\varepsilon \varepsilon]_{Y}}{n}}$

$\mathrm{X}$ ve $\mathrm{Y}$ yönündeki hatalardan Eşitlik 3'e göre belirlenen karesel ortalama hata, kıyı çizgisinin konum doğruluğuna ilişkin uygun bir istatistiktir (Aydın, vd, 2018). Eşitlik 3' e göre konum doğruluğu, 1.578 metre olarak hesaplanmıştır.
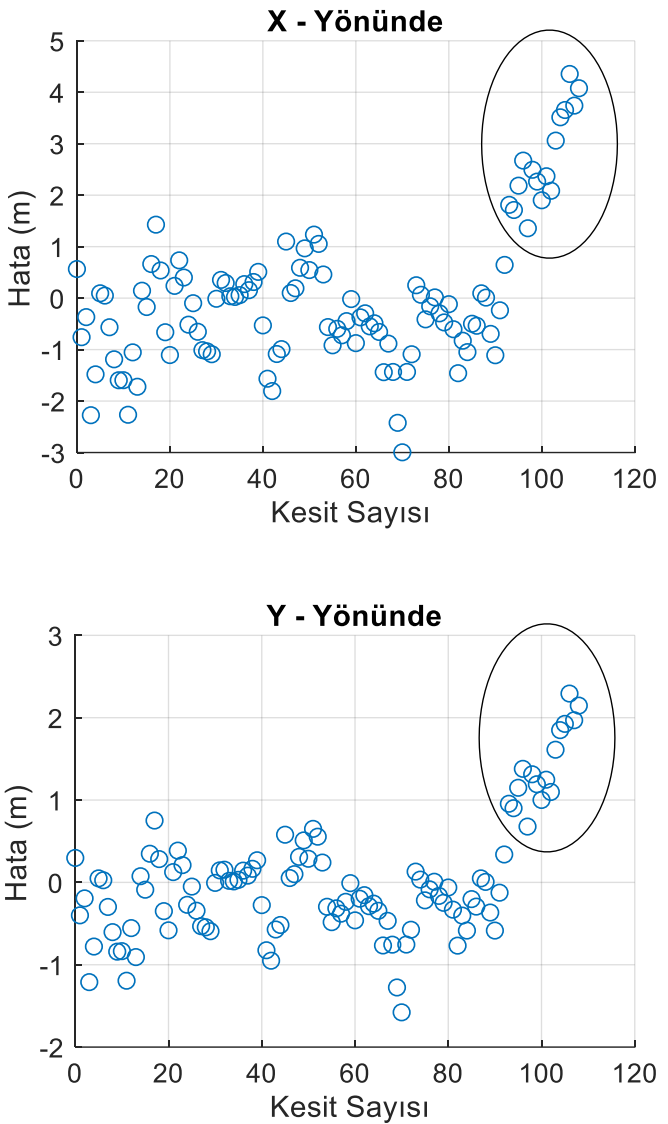

Şekil 6. X ve Y Yönündeki Hatalar

Şekil 6' dan, $\mathrm{X}$ ve $\mathrm{Y}$ yönündeki hatalar incelendiğinde, elips içine alınan kısımların dalga etkisinden kaynaklandığ 1 ve sistematik hata içerdiği anlaşılmaktadır. 93-108 no.lu kesitlere denk gelen verilerin değerlendirmeden çıkarılması ile tekrar yapılan hesaplamalarda konum doğruluğu 1.068 metre olarak belirlenmiştir.

\section{SONUÇLAR VE ÖNERÍLER}

Tablo 1'den de görüleceği üzere, Uluslararası Hidrografi Örgütü tarafindan yayınlanan Hidrografik Ölçme Standartlarında özel derece alanlarda kıy çizgilerinin belirlenmesinde konumlandırma doğruluğu (\%95 güven aralığı) 10 metre, $1 \mathrm{a}, 1 \mathrm{~b}$ ve 2 . derece alanlarda ise 20 metredir.

Çalışma bölgesine ait ortofoto görüntülerin 3 farklı kişi tarafından elle sayısallaştırılması sonucunda, 109 adet kesit üzerinde yapılan değerlendirmeler ile belirlenen kıyı çizgisinin konum doğruluğu $(\sigma) 1.578$ metredir. Bu değer $\% 95$ güvenirlik seviyesinde $(2 \sigma) \quad 3.156$ 
metredir. Dalgadan kaynaklanan sistematik hatalı ölçüler çıarılarak yapılan hesaplamalarda kıy çizgisinin konum doğruluğu $(\sigma) 1.068$ metre, $(2 \sigma)$ ise 2.136 metre olarak belirlenmiştir. Hem dalgalı hem de dalga etkisinden arındırılmış olarak belirlenen kıyı çizgilerinin konum doğruluklarının, IHO'nun öngördüğü kıyı çizgisi belirleme doğruluklarını karşıladıkları görülmektedir.

Ölçmelerin yapıldığ tarihte havanın parçalı ve az bulutlu, hava sicaklığının $25^{\circ} \mathrm{C}$ ila $29^{\circ} \mathrm{C}$ aralığında olduğu, rüzgarın Batı Karadeniz'de batı ve kuzeybatıdan 3 ila $5(20-40 \mathrm{~km} / \mathrm{sa})$, zamanla 4 ila $6(30-50 \mathrm{~km} / \mathrm{sa})$ kuvvetinde estiği, dalga yüksekliğinin ise 1.0 ila 2.0 metre civarında olduğu o haftanın meteoroloji raporlarından anlaşılmaktadır.

Dalga hareketinden kaynaklanan köpükler nedeniyle suyun kıyıya değdiği yerlerde, durgun deniz durumuna göre farkliliklar oluşmuştur. Dolayısıyla RTK GNSS ölçüleri ile elle sayısallaştırma sonucundaki hatalar denizin dinamik yapısından kaynaklanmıştır. X yönündeki hataların $\mathrm{Y}$ yönündekilerinden büyük çıkmasının nedeni de dalga etkisidir. Her ne kadar kıyı çalışmalarında denizin durgun olduğu zamanlarda uçuş ve ölçü önerilmekteyse de, pratikte bu neredeyse Karadeniz için olanaksızdır.

Uzun bir sahil şeridine sahip olan ülkemizde kıyı çizgilerinin ölçümünün, gerçek zamanlı kinematik GNSS yöntemlerine nazaran hem maliyet hem de zaman ve emek tasarrufu açısından İHA' lar kullanılarak yapılmasının tercih edilebilir olduğu düşünülmektedir.

Bunun yanında, ülkemizde dik yamaçlı ve ulaşması güç kıyılarımız da bulunmaktadır. $\mathrm{Bu}$ alanlardaki ölçmeler için de insansız hava araçlarının bir firsat olduğu görülmektedir.

Elle yapılan sayısallaştırmalardan elde edilen konum doğruluklarına bakıldığında, sadece kıy1 çizgisinin ölçümü değil, denizlerde gemilerin navigasyonu sirasında yararlanılan seyir yardımcılarının (şamandıra, vb.) da konumlarının yine insansız hava araçları yardımıyla belirlenmesinin mümkün olacağ 1 düşünülmektedir.

\section{TEŞEKKÜR}

$\mathrm{Bu}$ araştırma çalışmasındaki veriler $115 \mathrm{Y} 718$ no.lu TÜBİTAK projesi kapsamında toplanmıştır. Bu çalışma için söz konusu proje verilerini paylaşan proje yürütücüsü Prof. Dr. Bülent BAYRAM' a teşekkürlerimi sunarım.

\section{KAYNAKÇA}

Aydın, C., Aykut, N.O., Akpınar, B. (2018). GNSSPPP ile Elde Edilen Düssey Yerdeğiştirmenin Doğruluğu, Afyon Kocatepe Üniversitesi Fen ve Mühendislik Bilimleri Dergisi, 18 (2018) 015506 (605615).

Aydın, Ö., Aykut, N.O., Akpınar, B., Ata, E. (2005). RTK GPS Yöntemiyle Kiyı Çizgisinin Ölçülmesi, 5. Ulusal Kıyı Mühendisliği Seтроzуити Bildiriler Kitab1, s.467-478.

Bayram B., Avşar E. Ö., Şeker D. Z., Kayi A., Erdoğan M., Eker O., Janpaule I., Çatal R. H. (2017). The Role Of National And International Geospatial Data Sources In Coastal Zone Management. Fresenius Environmental Bulletin, 26(1), pp. 383391.

Bayram B., Demir N., Ogurlu M., Catal R. H., Seker D. Z. (2016). 3D Shoreline Extraction Using Orthopoto-Maps and LIDAR. In: 37 th Asian Conference on Remote Sensing, Sri Lanka, Colombo, pp.15.

Barazzetti, L., Remondino, F., ve Scaioni, M. (2010). "Automation in 3D reconstruction: results on different kinds of close-range blocks," Int. Arch. Photogramm. Remote Sens. Spat. Inf. Sci., vol. XXXVIII, no. Part 5, pp. 55-61.

Cheng, L., Tong, L., Liu, Y., Li, M. and Wang, J. (2014). "Automatic Registration of Coastal Remotely Sensed Imagery by Affine Invariant Feature Matching with Shoreline Constraint," Mar. Geod., vol. 37, no. 1, pp. 32-46.

Dji, (2018). Phantom Pro 4 Manual, from https://www.dji.com/phantom-4pro?site $=$ brandsite $\&$ from $=$ landing $\_$page

Dornbusch, U., Robinson, D.A., Moses, C.A., Williams, R.B.G. (2006). "Chalk coast erosion and its contribution to the shingle budget in East Sussex", Z. Geomorphol. N.F., 144, 215-230.

Esposito, G., Salvini, R., Matano, F., Sacchi, M., Danzi, M., Somma, R., Troise, C. (2017). "Multitemporal monitoring of a coastal landslide through SfM-derived point cloud 
comparison," Photogramm. Rec., vol. 32, no. 160 , pp. 459-479.

Gonçalves, J.A., and Henriques, R. (2015). "UAV photogrammetry for topographic monitoring of coastal areas," ISPRS J. Photogramm. Remote Sens., vol. 104, pp. 101-111.

IHO, (2008). IHO Standards for Hyrdographic Surveys, Special Publication No:44, 5th edition, Monaco.

Nikolakopoulos, K.G., Kozarski, D. and Kogkas, S. (2017). "Coastal areas mapping using UAV photogrammetry," Earth Resour. Environ. Remote Sensing/GIS Appl. VIII, no. October 2017, p. 23.

Peter, K.D., d'Oleire-Oltmanns, S., Ries, J.B., Marzolff, I. and Ait Hssaine, A. (2014). "Soil erosion in gully catchments affected by land-levelling measures in the Souss Basin, Morocco, analysed by rainfall simulation and UAV remote sensing data," Catena, vol. 113, pp. 24-40.

Stöcker, C., Bennett, R., Nex, F., Gerke, M. and Zevenbergen, J. (2017). "Review of the current state of UAV regulations," Remote Sensing, vol. 9, no. 5 .

Yoo, C.I. and Oh, T. S. (2016). "Beach volume change using UAV photogrammetry Songjung beach, Korea," Int. Arch. Photogramm. Remote Sens. Spat. Inf. Sci. ISPRS Arch., vol. 41, no. July, pp. 12011205.

Yüksel, Y., ve Özkan Çevik, E. (2005). Liman Mühendisliği, Deniz Mühendisliği SerisiNo:3, Arıkan Basım Yayım Dağıtım Ltd.Şti., İstanbul.

Yüksel, Y., Çevik, E., Çelikoğlu, Y., (1998). Kıyı ve Liman Mühendisliği, TMMOB İnşaat Mühendisleri Odası, Ankara Şubesi, Alaz Ofset, Ankara. 